\title{
Memórias de Caos e Cosmos nos Cristianismos das Origens: uma análise narrativa do Apocalipse de João
}

Kenner Roger Cazzoto Terra*

\section{Resumo}

Durante muito tempo o Apocalipse de João foi lido como descrição da realidade dos cristãos no Império Romano, como se o texto pudesse ser reflexo de fatos decifrados pela linguagem apocalíptica. Neste texto, depois de superar as leituras histórico-sociais feitas no livro de Apocalipse, as quais tentaram demonstrar que ele foi uma espécie de mensagem cifrada para a criação de esperança a cristãos perseguidos por Roma, será apresentada a leitura que leva em consideração as estratégias narrativas para o estabelecimento discursivo não de esperança, mas de uma leitura pessimista e de terror. Para tanto, há a relação dialógica prevista pela narrativa entre enunciador e enunciatário, os quais compartilham o conjunto de textos que transitam na semiosfera.

Palavras-chave: Memória. Cosmos. Apocalipse. Narrativa. Caos.

\section{Abstract}

For a long time the Apocalypse of John was read as a description of reality of Christians in the Roman Empire, as if the text could be a reflection of facts deciphered by apocalyptic language. In this paper, after overcoming the social-historical readings of the Book of Revelation, which tried to show that it was a kind of ciphertext to the creation of hope to Christians persecuted by Rome, the reading will be presented that takes into consideration the strategies narratives to the discursive establishment not of hope, but a pessimistic reading and terror. To this end, there is a dialogical relationship envisaged by the narrative between enunciator and enunciatary, which share the set of texts that pass in the semiosphere.

Key-words: Memory. Cosmos. Apocalypse. Narrative. Chaos.

* Faculdade Unida de Vitória. Mestre e Doutor em Ciências da Religião (UMESP), Membro do Grupo Oracula de Pesquisa, doscente no programa de mestrado profissional (Faculdade Unida de Vitória - FUV) 


\section{Introdução}

O Apocalipse de João é um importante exemplo de estratégias narrativas da literatura cristã dos primeiros séculos. As imagens que surgem nessa obra do profeta João revelam um quadro de ordem a partir de uma estruturação mítica da realidade, que uma vez desfeita gera terror e desordem. Para essa instauração narrativa de terror, a linguagem cheia de imagens do grotesco é preservada. Assim, o livro de Apocalipse torna-se uma obra de instalação discursiva do terror, que é uma contra-argumentação à ordem prevista pelo discurso romano.

Primeiro, serão apresentadas as possibilidades de leitura de Apocalipse para, então, inserir este trabalho entre os que privilegiam mais a observação das estratégias narrativas do livro do que a sua adequação às realidades históricosociais de perseguição. Nesse sentido, o "contexto" é visto como a "memória do dizer", ou seja, a semiosfera judaico-cristã. Se o Império Romano tinha o discurso de um mundo coeso, pacífico e ordenado, no qual se integravam os âmbitos econômico, político e religioso, o discurso de Apocalipse dá indícios de desconstrução desse quadro, propondo outro olhar sobre a realidade. Este seria um contradiscurso, o qual se estrutura em diálogo com as imagens de caos comuns nas memórias da literatura enoquita. ${ }^{1}$ A preocupação será, então, identificar o "contexto" criado narrativamente. Para percebermos a construção do terror e caos narratológicos, olharemos a sequência narrativa temática ${ }^{2}$ das trombetas, selos e taças.

Por muito tempo, especialmente na exegese latino-americana, o livro de Apocalipse foi lido como um texto que refletia, ou nele subjaziam, realidades de opressão e até mesmo martírios causados pela violência estrutural impetrada pelo Império Romano sob a coroa de Domiciano. ${ }^{3}$ Nessa perspectiva, o Apocalipse foi escrito para ajudar os seguidores de Jesus a manterem a fé durante a desgraça, com a promessa de que a iminência do fim encerraria uma grande tribulação. A afirmação de Eusébio ("muitas foram

Como defende Carol Newsom, o que é característico em 1 Enoque 12-16 é a ruptura na ordem do universo (Cf. NEWSOM, 1980, p. 310-329).

2 Sequência narrativa é um termo técnico da Análise Narrativa e se refere a uma unidade narrativa composta por várias micronarrativas. Ser temática diz respeito à sua estratégia na composição da narrativa, pois demonstra como determinado tema é desenvolvido e a importância de cada micro no quadro narrativo.

3 Contudo, temos trabalhos realizados, no Brasil, que não seguem esse caminho. Pode-se citar o ensaio de Nogueira, que afirma categoricamente: não há, de fato, muitas informações sistemáticas contra cristãos na Ásia Menor sob Domiciano (Cf. NOGUEIRA, 2003, p. 23). 
Memórias de Caos e Cosmos nos Cristianismos das 379

Origens: uma análise narrativa do Apocalipse de João

as vítimas das crueldades de Domiciano" [Hist. Ecl. 3.17]) (THOMPSON, 2003 , p. 30) de que esse regente romano deu muitas provas de crueldade, sendo um dos que promoveram a perseguição contra os cristãos, era uma afirmação historicamente aceita. Alguns, diferentemente, leem o texto de Irineu (Adversus Haereses 5. 30. 3) e identificam as imagens de violência e morte de Apocalipse como espelho do período do reinado de Nero (FRILINGOS, 2004, p. 2-3). Ou seja, o texto é visto como uma porta de entrada para a realidade sangrenta, marcada por perseguições. Um exemplo dessa leitura está no clássico comentário de Carlos Mesters e Francisco Orofino (MESTERS; OROFINO, 2002), no qual encontramos ainda a expectativa de que o Apocalipse reflita, em algum nível, a realidade de perseguição vivida no Império Romano. Mesmo levando em consideração as dúvidas levantadas pelas pesquisas acerca da perseguição por Domiciano (81-96), os autores acreditam encontrar no livro de Apocalipse a vida real do Império Romano na Ásia. Como eles mesmos dizem:

Nota-se hoje que em alguns comentários há uma tendência para diminuir o impacto da perseguição no fim do governo do Imperador Domiciano (81-96) (...). O que imporá nesta questão talvez seja definir melhor o que se entende por perseguição. De fato, é possível e provável que não tenha havido uma perseguição explicita contra os cristãos, em nível global do Império, decretada por Domiciano (...). As alusões no livro do Apocalipse são demasiadas para serem negligenciadas ou desfeitas como sendo de menor importância (...). Mesmo não havendo informação explícita extrabíblica a respeito da perseguição na época de Domiciano, estas alusões do próprio Apocalipse também são uma informação histórica dos anos 70 e 110 d.C. (...). Como consequência desta pressão ideológica cada vez mais forte, havia também perseguição sangrenta (MESTERS; OROFINO, 2002, p. 47, 51).

Nesse ponto de vista, o livro do visionário João seria uma espécie de mensagem cifrada, uma janela para o mundo do Império, onde cristãos viviam diversas crises internas e externas. Desse modo, o livro se apresenta como espelho para uma comunidade cristã que, segundo os autores, está em franca separação do judaísmo.

Outro texto latino-americano que acompanha, com algumas modificações, essa perspectiva é a obra de Pablo Richard (RICHARD, 1996). Seguindo as afirmações de Paul Hanson (HANSON, 1983), de que a literatura apocalíptica surge sempre em espaços de privação, o Apocalipse é tratado por Richard como obra de setores marginalizados, pobres e humilhados, os quais produzem uma 
visão histórica ou teológica alternativa às dos dominantes. Assim, ele define três tipos de situações que os oprimidos podem viver e das quais podem nascer os textos apocalípticos: desintegração, perseguição e opressão. Para Richard, há uma realidade de opressão e exclusão por trás das linhas do texto que se materializavam no âmbito econômico, cultural, religioso, político, cotidiano e familiar.

A realidade de exclusão é uma situação pior que a exploração e a opressão, pois o excluído fica completamente fora e não conta: sua morte não afeta o sistema (...). O excluído não apenas vive sob violência dominante, mas, além disso, a violência entre os próprios excluídos (...). Este é o contexto social fundamental onde nasce o Apocalipse, sem negar situações de opressão permanente e de perseguição indubitáveis, que se deram da mesma forma (RICHARD, 1996, p. 48-49).

Ainda, aqui temos a presença da pretensiosa tentativa de reconstruções históricas a partir do texto de Apocalipse e mais um exemplo da maneira como o livro foi lido em terras latino-americanas. A existência de sofrimento e perseguição serve como pano de fundo para a leitura do texto.

Isso nos mostra um indício, mesmo que superficial, de como há algum tempo as estratégias de leitura e perguntas ao texto estão mudando. Isso não desqualifica as grandes contribuições desses autores e obras. Esses trabalhos acumularam uma gama de possibilidades de compreensão das imagens de Apocalipse como também juntou-se um bom número de informações a respeito do contexto histórico e social do mundo antigo dos primeiros séculos.

\section{Novos ares para a leitura de Apocalipse de João}

Desde o século XX, a pesquisa tem relativizado a imagem de um mundo cheio de violência e conflitos percebidos a partir da descrição do livro de Apocalipse, como se a obra equivalesse à situação concreta da vida das comunidades. Para importantes autores (alguns deles serão aqui apresentados) é mais frutífero olhar o livro de Apocalipse como estratégia narrativa, que acessa o discurso apocalíptico maior - que é uma constelação de tópicos (CAREY; BLOOMQUIST, 1999) - para persuasão retórica.

Assim, a partir dos indícios narrativos de tribulação, Thompson mostra como estamos diante da construção retórica da realidade, a qual não reflete diretamente a realidade do mundo que cerca o visionário, mas é a "verdadeira" condição dos seus ouvintes à luz do mundo percebido pelo profeta. O conflito 
não está na perseguição ou qualquer privação, mas na divisão dos dois mundos criados discursivamente: o do profeta e o mundo romano (THOMPSON, 1986, p. 169).

O conflito sugerido por João não é entre elementos existentes no cristianismo, mas entre a sua compreensão de mundo e a do universo coerente encarnada no Império Romano. Roma oferece na esfera pública uma ordem coerente que une as realidades religiosa, social, econômica, política. (...) Roma oferece "conhecimento" por meio do qual os asiáticos urbanos poderiam "mover-se com certa confiança na vida cotidiana". O visionário julga que esse "conhecimento" público seja falso e oferece para os cristãos, por meio da verdade do Apocalipse, um conhecimento esotérico para integrar e ordenar suas vidas (...). Ele procurou de várias maneiras possíveis afinar diferenças e distinções entre a sua visão de mundo e a romana, a fim de que seu conhecimento esotérico e verdadeiro não fosse confundido com ou diluído no falso conhecimento publicado pelo Império Romano. Tribulação como um tema hiperbólico no mundo literário de João funciona não como análise durante uma tensão entre fé e realidade sociopolítica, mas como uma expressão do conflito que ele percebeu entre os dois "mundos". Sua oposição é expressa miticamente no simbolismo de João pela equivalência de Roma como o Mal, forças demoníacas opositoras à fé dos seguidores de Deus (THOMPSON, 1986, p. 166).

O Império Romano oferecia aos seus cidadãos a expressão retórica, materializada no Imperador e na Pax Romana, de ordem e coerência que unia os âmbitos sociais mais fundamentais da vida comum. Para o profeta João, essa ordem era falsa e deveria ser vista por outro ângulo, visionariamente, para se perceber o lado caótico que o sistema representava. Para dar autoridade ao seu discurso e leitura de mundo, ele começa seu texto demonstrando que tipo de força tem a sua narrativa: revelação de Jesus Cristo (1,1) (COLLINS, 1977, p. 329-343).

$\mathrm{O}$ autor acredita que o problema esteja na retórica do Império e na interpretação do visionário. A paz e a prosperidade do discurso da sociedade romana, no seu ponto de vista, não podem ser celebradas pelos cristãos fiéis: as sete cabeças da besta são as sete colinas de Roma (Ap 17,9); elas também são sete imperadores romanos (Ap 17,10). Roma é Babilônia, a prostituta que cavalga a besta escarlate, que cai e que se tornou uma prisão (Ap 18,2; 20,7). No Apocalipse a ordem política de Roma é totalmente corrupta, pertencente ao reino satânico. Assim, Thompson defende que o conflito está na perspecti- 
va de João, e não na sociedade. E ainda, a crise é uma orientação própria do gênero apocalíptico, e não necessariamente a realidade social. Como ele diz, a situação de crise é um "topos" no gênero apocalipse (THOMPSON, 1990, p. 175). Desse modo, Thompson mostra o Apocalipse de João como discurso que desqualifica retoricamente ao usar os topoi próprios do gênero para mostrar que o discurso de ordem e paz não era real, pois, por intermédio de meios autorizados, como a visão, interpreta-se o mundo romano de maneira completamente diferente. O que há são caos e perseguição prevista.

\section{Caos, cosmos: topografia da ordem e da desordem no en- redo de apocalipse}

Nas estratégias narrativas de Apocalipse percebe-se, na sua forma, a relação de textos como fios unificadores internos do enredo que servem não somente a esse propósito, mas também como estruturadores do conteúdo de movimentação de caos e ordem - por exemplo, 17,1 e 21,9 mostram as relações de caos e cosmos (prostituta, esposa do cordeiro). Isso fica ainda mais claro com o surgimento do dragão, caído do céu com um terço das estrelas (12,3-4), e seu aprisionamento em 20,2-4.

Esse efeito de sentido é realizado, como está sendo dito, também pelo conteúdo. Os elementos semânticos desses quadros narrativos têm, como uma espécie de sintaxe para os seus discursos, as memórias preservadas na semiosfera, estas em constantes explosões e encontros semióticos que alcançam suas potencialidades no Apocalipse de João.

Encontramos na obra diversos personagens no jogo dualista do caos e da ordem. Isso não é difícil de se perceber nos textos cosmogônicos que também faziam parte da memória cultural da tradição judaica e cristã e que foram traduzidos por diversas partes da semiosfera. Encontramos Pyton, Leto e Apolo; Sete, Isis, Horus; Tiamat, Marduc; Baal, Yam e outros. No livro de Apocalipse, nas seções das três séries de sete pragas, há a apresentação de personagens redondos tanto de um lado como de outro. Isso mostra, além da sua importância no desenvolvimento da narrativa, a saturação do ponto de vista narrativo do avaliador, que faz claramente o leitor dar as respostas satisfatórias de empatia, simpatia e antipatia. Por isso, é possível convocar para sair daquele espaço que representa o lugar dos personagens de caráter antipático: “...saí dela, ó meu povo” (18,4a).

Na linguagem das narrativas, é perceptível a utilização do monstruoso e violento relacionada às expressões do caos. Essa linguagem está perpas- 
sada pelo grotesco. Segundo R. Graulund e D. Edwards, o monstruoso é classificado como corpo grotesco por conta do seu caráter híbrido, composto por diferentes elementos. A figura física grotesca mistura o humano com o não humano, o que tem significado de corrupção (GRAULUND; EDWARD, 2013 , p. 37): os atributos humanos das figuras grotescas são combinados com formas distorcidas e desproporcionais, as quais incorporam o animalesco ou, em alguns casos, formas vegetais de vida. Esses estudiosos continuam caracterizando o grotesco no monstruoso, revelando que tais seres costumam habitar em lugares distantes (GRAULUND; EDWARD, 2013, p. 41). A imagem do repulsivo, evidenciada pelas formas misturadas, reflete o interior da criatura, sua monstruosidade interna se desvenda na violência e na brutalidade (GRAULUND; EDWARD, 2013, p. 39). Analisando as figuras homéricas, Graulund e Edwards assinalam que a carnificina e o muito sangue são próprios do lugar do grotesco. Essas figuras, mesmo que mostrem os limites da corporeidade, têm a função do terror e do medo: "mas elas podem também gerar medo, ainda que para a estabilidade, por meio da descrição assustadora" (GRAULUND; EDWARD, 2013, p. 40).

O grotesco intenta demarcar identidade: o outro, o diferente. Verifica-se a demonização do outro, a desqualificação. O monstruoso, deformado, híbrido, misturado, tem relação com o terror e o medo na definição cultural do outro, do corpo e da cultura na grotescalização. Nesse sentido, o Apocalipse de João mostra a realidade de Roma a partir da realidade. O grotesco revela a interpretação que o visionário faz do sistema romano: monstro do caos, aterrorizante, híbrido e desestabilizador. Qualquer adequação seria um absurdo, porque tal relação não é aceitável - isso se os ouvintes previstos por João quiserem ser livres das pesadas e aterrorizantes mãos dos que não são do cordeiro $(9,4 ; 14,14$ ss. etc.). O grotesco, também presente nos textos da cultura, revela a identidade construída pelo visionário. Para que sua interpretação seja valiosa, ele precisa acessar uma sabedoria além-mundo, por intermédio da qual se pode ver o que não é visto, interpretar radicalmente a realidade, gerando peso à autoridade do narrador, aqui onisciente.

\section{O monstruoso e o caótico: Antítese do Cosmos}

Depois da abertura epistolar (1,1-3), da visão gloriosa de João e do envio das cartas às igrejas $(1,4-3,22)$, começa o quadro de terror e punição por meio das pragas em série de sete. Como temos mostrado, elas estão 
interconectadas por indícios narrativos na estrutura maior de caos-ordem. Contudo, em termos de sincronia narrativa 4,1-11, é um quadro de ordem em linguagem litúrgica: ser celestial sentado, organização de anciãos, os sete espíritos de Deus, os viventes, a kedushá, os seres viventes. No capítulo 5 começa o drama que tem início na apresentação do rolo com os sete selos $(5,1)$. Após uma exposição densa de adoração (5,6-14), 6,1 volta à cena dramática do rolo e dos selos, o que desencadeia um conjunto de julgamentos com um misto de ação maligna, punição divina e salvação definitiva dos fiéis. Em 6,1-16,16, com uma conclusão da seção anterior e abertura para a posterior (16,17-21), há uma descrição da tensão entre o caos e a ordem, tendo o capítulo 12 como ponto importante para esse quadro. Em 16,17-22,9, verifica-se o início e o ápice da organização do mundo imaginado por João, que culmina na Nova Jerusalém (21-22,9).

As partes da seção com as pragas, as três séries, estão interconectadas por causa das estratégias de ricochetes e fio condutor. O sétimo selo $(8,1)$

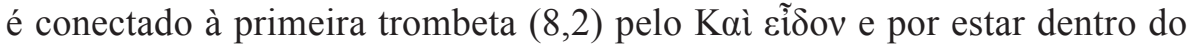
sétimo selo. Dentro das trombetas estão 10-11,19 formando os dois primeiros "ais". As taças são introduzidas pelo bloco 12-14, que se liga por

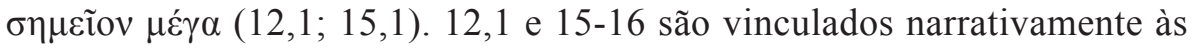
primeiras duas pragas por 11,19 a com 15,5 .

As séries das pragas no Apocalipse são aplicações escatológicas das pragas do Egito (Êx 7-12). Inclusive, se entre a sexta e sétima trombetas está 10-11,13, no livro do Êxodo, entre a nona e a décima pragas se encontra a instrução sobre a Páscoa (Êx 12) (AUNE, 1998, p. 499). Essas imagens da Bíblia Hebraica servem como condutoras para a leitura do caos, com a linguagem de terror ao lado das tradições apocalípticas. As pragas atingem todo o cosmos, das relações sociais às estruturas naturais. Estas vivem as condições finais da existência, como estava previsto no Testamento do Dan

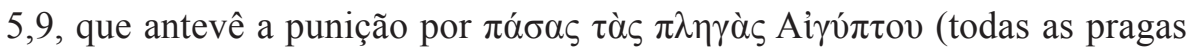
do Egito). Em 3 Apocalipse de Baruc 16,3 fala-se de gafanhotos, lagartas, ferrugens, granizo e relâmpagos como punição aos filhos com demônios (AUNE, 1998, p. 500). Essas imagens podem ser analisadas, bem como, as ocorrências do discurso de construção do caos, com as imagens próprias da semiosfera judaico-cristã. 


\section{As estrelas que caem do céu e seres que sobem do Caos: 6,$12 ; 8,10-13 ; 12,1-13,1-10$}

O Livro de Apocalipse interpreta narrativamente. Como bem percebeu José Adriano Filho, "o Apocalipse deve-se principalmente à linguagem mítica que o livro utiliza, principalmente a do conflito primordial, que indica a instalação das forças demoníacas na esfera política e humana, transformando-a num verdadeiro caos" (ADRIANO FILHO, 1999, p. 100). Se há um discurso de ordem, no qual Roma promove a sua estrutura imperial, João vai ao céu, como nos textos de viagem além-mundo (THOMPSON, 1990, p. 193), e acessa uma sabedoria maior para legitimar a sua contranarrativa. Thompson chama as narrativas maiores, as do sistema romano, de "conhecimento majoritário". O narrador faz a sua crítica pública da falsa ordem de mundo (DUFF, 2011, p. 9) a partir da semiosfera judaico-cristã, a qual preserva imagens e expressões de caos em estrutura topográfica dos textos canonizados na cultura, outras da literatura bíblica e os espetáculos romanos (FRILINGOS, 2004, p. 11).

Dessa forma, pode-se entrar nas visões e seu conteúdo para se perceber como o narrador, pelo menos enquanto autor implícito, pressupõe as memórias na cultura e como ele as articula para a construção do terror. Paul Duff, ao falar dos capítulos 6 e 9, acerta quando diz que João faz acusações ao seu rival por meio da retórica da insinuação ao utilizar homologia e ironia, às quais emprega em todo o Apocalipse para construir o seu mundo dualista narrativamente. No entanto, ele erra em achar que a questão seja uma querela interna. Fazendo uma leitura feminista, Duff acredita que seria uma linguagem injusta de violência contra a liderança de Jezabel e seus seguidores (DUFF, 2011, p. 16). Não há dúvidas de que as cartas estão em diálogo polêmico com alguns líderes nas comunidades, mas é o problema da aproximação com interesses do Império e a aceitação do discurso de ordem romana que constituem o seu grande problema. As pragas, além de revelarem o caos como verdadeira realidade, são também expressões das punições aos que não têm a marca $(9,4)$, aos que desejam o desestímulo à assimilação do discurso ou, como diria Thompson, o conhecimento público romano.

No capítulo 6,1-7, o livro é aberto. A liturgia de 9b-14 é um interlúdio dramático que cria o suspense necessário para a abertura dos selos. O mesmo cordeiro $(5,6)$, que é actante da ação transformadora, inicia a abertura dos selos. A História será descortinada como um filme, com cenas ligadas umas às outras. Os quatro primeiros selos representam quatro cavalos. O primeiro, branco; o segundo, vermelho; o terceiro, negro; o quarto, verde. Esses cavalos trazem à 
memória Zacarias 1,7-11 (AUNE, 1998, p. 390). O primeiro selo traz um cavalo branco com força, com liderança e vitória. $\mathrm{O}$ cavalo vermelho tem em sua

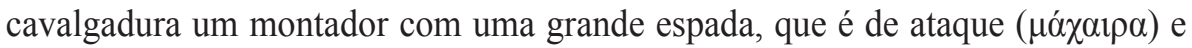
que está em relação antitética com a eipńvๆv. A espada é para derramamento de sangue (KITTEL; FRIEDRICH; BROMILEY, 1995, p. 525). Esse instrumento é somente um complemento da sua capacidade de criar as intrigas necessárias entre os homens, a fim de que se matem. Em 1 Enoque 10,12, os gigantes são colocados uns contra os outros para serem destruídos: "coloca-os uns contra os outros, para que se matem mutuamente". Se em 1 Enoque era uma ação de ataque aos causadores de caos, aqui a imagem serve para mostrar a instauração e revelar como o narrador lê as relações sociais. Sobre o cavalo negro havia

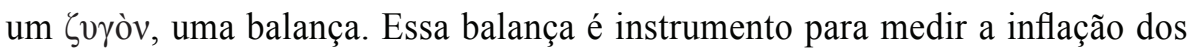
preços, numa imagem de caos nos valores dos bens básicos tanto para as pessoas (trigo) como para os seus animais (cevada). O valor de um salário do dia revela o descontrole de preços próprio dos momentos de fome ou de guerra

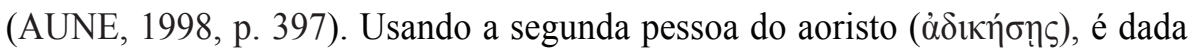
a ordem para o cavaleiro não causar problemas inflacionários ao vinho e ao óleo $(6,6)$, que seriam os produtos de luxo, mostrando ainda mais a realidade de desigualdade de valores e a desordem econômica. O cavalo verde é montado pela morte $(6,7)$, uma personalização da realidade de destruição causada pelas espadas e balanças dos cavalos anteriores. O hades, lugar dos mortos na tradição grega, é personagem figurante na narrativa, enquanto a morte é protagonista provocada por diversas forças: espada, fome, peste e feras.

O quinto selo abre uma nova cena na narrativa. Se até 6,8 o texto não dá detalhes do espaço dos verbos, aqui as personagens coletivas, "as almas imoladas", estão no altar, lugar do sacrifício. O caos narrativo dos quatro primeiros selos não atinge somente os ímpios, os que não têm a marca de 9,4 , mas tem impacto até sobre os justos. Por causa da Palavra $(6,9)$, prevê-se que essa situação de paz anunciada não representa o que está prestes a acontecer. Mártires serão os que entendem a interpretação do visionário de se afastarem das relações com o Império e seus discursos. Eles são tratados de forma especial porque são personagens com os mesmos traços do cordeiro $(4,6)$ que abre os selos. Quem tem o poder de abrir os selos também beneficia seus pares. Narrativamente se cria um espaço de tempo entre o quarto e o quinto selos, bem como entre a quarta e a quinta trombetas, pois esse sexto selo será a intensificação da cena de terror e caos. 
É nesse espaço-tempo da narrativa que se nota uma das imagens enoquitas de instauração de caos que se perenizou na semiosfera e que aparece na construção narrativa de João. Há um terremoto, o sol torna-se preto, a lua inteira se torna como sangue e as estrelas caem do céu, precipitando-se sobre a terra $(6,12)$. Como desdobramento, o céu é enrolado tal qual um pergaminho, montanhas e ilhas são removidas, todas as pessoas de diversas classes sociais são aterrorizadas e pedem a morte, porque melhor seria morrer do que enfrentar o dia da ira do cordeiro $(6,16)$.

A imagem das estrelas caindo joga com a ambiguidade presente no termo $\alpha \sigma \tau \eta \dot{\rho} \rho$ e com os textos da cultura judaica e cristã. Isaías 34,1-17, ao descrever o julgamento de Edom, fala sobre o exército do céu apodrecer (a) usando

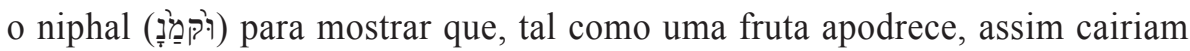
as estrelas do céu. O texto ainda esclarece isso no versículo 4, usando um

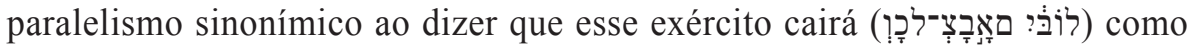
as folhas da vide e da figueira. Na LXX, esse exército é traduzido como $\tau \grave{\alpha}$ á $\sigma \tau \rho \alpha$, "estrelas". No Apocalipse de Marcos $(13,21)$, com seus paralelos em Mateus 24,29 e Lucas 21,26, as estrelas que caem são apresentadas em linguagem escatológica. Por isso essas estrelas, que poderiam ser simplesmente astros do céu, às vezes representando governos (Is 14; Is 34), ganham conotações escatológicas. Em 1 Enoque 86,1-2, a estrela que cai é um ser celestial precipitado do céu e que se transforma em um animal, bem como, as demais estrelas do mesmo capítulo. No Livro Astronômico (1En 72-82) estrelas e anjos se confundem. Assim, falar em estrelas que caem do céu é, provavelmente, na semiosfera judaico-cristã, expressão de desordem cósmica localizada em temporalidade escatológica. No livro de Apocalipse $(8,10 ; 9,1 ; 12,4)$ estrelas que caem do céu são seres precipitados dos céus e que têm força de desordem.

Assim sendo, o movimento de estrela em queda é vinculado e está em diálogo com textos da cultura, bem como, ativa memórias em relação dialógica com o Apocalipse. Essa realidade do caos é percebida $(6,17)$ como o início do "grande dia da sua ira". O texto confirma a imagem do começo do bloco (4-5), que é o controle do cordeiro, pois esse momento de terror interpretado pelo visionário tem espaço para uma expectativa de fim, também interpreta a realidade, torna-se uma narrativa de instauração de caos. O mundo é, para João, estrelas que caem do céu - está em caos.

A narrativa, para gerar mais tensão e expectativa sobre o leitor implícito, cria a cena de 7,1-17, que pode ser lida como continuidade do sexto selo. No sétimo selo, estão inseridas as sete trombetas. No céu, o cordeiro abre o selo 
e ocorre um silêncio $(8,1)$. Esse tempo de espera, com o uso da conjunção grega de comparação (ஸ́s) (ARNDT; DANKER; BAUER, 2000, p. 1.104), é caracterizado como meia hora ( $\dot{\omega} \varsigma \dot{\eta} \mu \mathrm{i} \dot{\rho} \iota \mathrm{ov})$. Nesse ponto da narrativa temos uma elipse qualificada, mas que não determina, como acontece com tais estratégias narrativas, claramente esse período. O tempo de espera é comparado a meia hora da cronologia histórica, mas como a narrativa é construída no tempo mítico, ele não pode ser datado. É simplesmente uma indicação narrativa estratégica de tensão. Nos versículos 2-5 há uma liturgia para o início das séries de trombetas: tem incensário e altar diante do trono, o que lembra 6,9-11. Essa é uma introdução para as cenas de terror que se seguirão, pois já são antecipadas pelo versículo 5 .

A primeira trombeta é tocada e caem sobre a terra granizo e fogo $(8,6)$. Esses dois elementos, segundo as tradições de viagem além-mundo, estão no céu, no mesmo espaço do trono. Assim como no versículo 5, os elementos do céu (fogo do altar) servem como munição para atacar a terra - eles estão misturados com sangue. Nessa trombeta, um terço da terra, das árvores e de toda a vegetação se queimaram. Na segunda trombeta, uma montanha de fogo é lançada no mar e um terço dele se transforma em sangue: como consequência, um terço dos animais aquáticos são mortos e a mesma quantidade de embarcações é destruída. Vários aspectos do cosmos são destruídos (8,7.9.10.11.12; $9,15.18)$, gerando uma imagem de desordem, que atinge pessoas, grupos, trabalhos e ecossistemas: a criação é abalada.

É nesse contexto narrativo que aparece o terceiro anjo e toca a trombeta. Nesse momento, diz o texto que uma grande estrela (como em 6,13), ardente

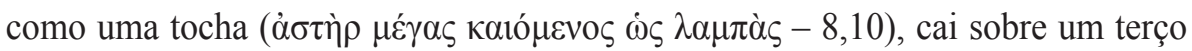
dos rios e suas nascentes. Essa estrela é identificada com o nome 'A $\psi \imath v \theta$ os. Tal personagem é plana e caracterizada por um só traço - o seu próprio nome, o que é o bastante para descrever as suas consequências: a terça parte da água é convertida em absinto. Na Bíblia Hebraica (Dt 29,17; Lm 3,15; Jr 19,14;23,15), ingerir essa substância extremamente forte e amarga seria um sinal de julgamento (ROLOFF, 1993, p. 111). O amargor das águas matou os homens. Nesse movimento de estrela, agora nomeada, seu nome é exatamente a sua consequência. À luz do que está dito, percebe-se que a ideia de descer, cair em uma topografia inserida no tempo escatológico serve como conteúdo para mostrar a realidade prevista e já observada discursivamente na narrativa do visionário.

Na sétima trombeta, depois do segundo "ai" $(11,14)$, surge uma cena de batalha cósmica com clara linguagem do mito do combate do mundo antigo 
(COLLINS, 2001, p. 207-221). A narrativa, como tem feito até aqui, apresenta um narrador onisciente, que conhece as coisas que estão acontecendo nas esferas mais imperceptíveis. Ele narra que há um sinal no céu: uma mulher vestida com o sol, que tem a lua sob os pés, uma coroa de doze estrelas sobre a cabeça. Ela está grávida, com dores, aos gritos e em trabalho de parto (12,1-2). Essa mulher, como personagem redonda, fecha a descrição com detalhes sobre si. Surge outro sinal colocado ao lado do primeiro. É um ser também cósmico, um $\delta \rho \alpha ́ \kappa \omega v$ (dragão), cuja cor era de fogo, com sete cabeças, dez chifres e com dez coroas. Ele não está sozinho. Sua cauda derruba um terço das estrelas do céu, lembrando as pragas anteriores. Esse ser celeste é identificado no versículo 9

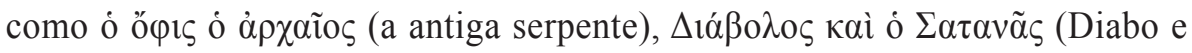
Satanás). O ser grotesco ataca o filho daquela mulher (12,4-5). O menino, diz o texto, seria aquele que resgataria - ou governaria - as nações, o que será possível nos capítulos finais de Apocalipse. O menino é levado para o céu, junto ao trono divino, e a mulher foge para o deserto $(12,6)$. Depois disso, constrói-se uma imagem de batalha cósmica com duas forças opostas: de um lado o dragão e seus anjos (aquele um terço do céu - 12,4); de outro, Miguel e seus anjos. São duas forças: uma do caos e, outra, da ordem.

Nas narrativas cosmogônicas da Mesopotâmia e nos mitos do combate no mundo antigo, o dragão representante do caos é destruído por sua contraparte e a ordem, que seria a criação, é instaurada. A ideia dos seres do caos contra Javé está em vários lugares da Bíblia Hebraica, que é uma imagem da criação. A mais conhecida é Gênesis 1,2, que fala doșini (tühôm), o abismo primordial, e que tem ecos com a Tiamat da tradição cosmogônica mesopotâmica e outras do mundo antigo. Em Jó 26,12; Salmos 74,12-13; Isaías 27,1; Isaías 51,9-10 e outros, Deus vence os seres ligados ao mar primordial, todos esses personagens do caos, o que possibilita a criação. A volta do cativeiro em Isaías 51,9-10 é interpretada cosmogonicamente: o caos é a experiência de exílio, que é resolvido com o retorno. Em Isaías 27,1, os seres vencidos por Javé são os seres do caos, o que a LXX traduz como dragão.

Na LXX, Leviatã, serpente escorregadia, serpente torcida e Tannin são traduzidos pela expressão dragão; seres do caos que estão nas narrativas cosmogônicas e que aparecem na Bíblia Hebraica em alguns lugares em combate com Javé. Em Apocalipse 12,7-12 se cria um dualismo rígido. De um lado, as forças do caos: o dragão e um grupo de estrelas que ele arrastou. De outro, Miguel e seus anjos. A batalha é vencida no céu e a ordem é restabelecida. Mas como o dragão cai na terra e continua a perseguição à mulher e seus filhos, ela 
ainda não chegou ao seu final primordial. Como nas narrativas preservadas na cultura, com seus temas de instauração de caos, especialmente na linguagem enoquita, o ser ou seres que caem são forças que promovem o caos e desordem. As fronteiras são transgredidas e a realidade é descrita de maneira grotesca/ monstruosa, como a imposição do dragão. Nos versículos 13-17, a luta e a perseguição se estendem aos filhos da mulher porque o vômito de água não a destruiu. Roma é descrita como representante não da ordem, mas do caos. Há o contradiscurso, no qual a linguagem mítica dá cores a uma realidade que existe no mundo da narrativa.

A batalha ainda não está no fim; ela agora se instaura na terra. Outro ser caótico surge no capítulo 13. Ele está associado ao dos capítulos 12 e 17 por ter as suas características $(12,2)$, receber o seu trono e sair do mar $(17,8)$. Essa besta que sai do mar lembra Daniel 7, que carrega a linguagem de seres caóticos vinculados ao espaço marítimo (Yam). Daniel, assim como João, caracteriza estratos governamentais como manifestações do caos. O dragão da linguagem mítica tem sua realização na terra; é a besta que sai do mar $(13,1){ }^{4}$ A ele também está vinculada a besta que sai da terra, que fala como o dragão $(13,11)$. A estas estão relacionadas outras duas: 11,7 e 17,9. Essas figuras são imagens ligadas com o sair das profundezas do abismo, que podem ser colocadas ao lado da expressão mar, de onde saem os seres caóticos.

Tais imagens impregnam a narrativa com o terror do caos. $\mathrm{O}$ visionário vê a presença na estrutura do sistema da própria realização das forças do dragão, que é o próprio Satanás das memórias apocalípticas. Para essa construção narrativa, emprega-se a ideia de seres que caem ou outros que sobem do abismo. Eles não são vários, mas um que, narrativamente ligado por representações e repetições de imagens, interpreta a realidade miticamente: Roma é caos. Aqueles associados a ela e seus discursos seriam, também, fadados ao mesmo destino (17-19). O cântico de 14,6-8 é somente um presságio do que se concretizaria em 17-19: a queda da prostituta. Depois da última batalha (19,11-21) acontece, então, a ordem do caos, o julgamento do ser caótico.

Para construir narrativamente a ordenação, em 20,1-4 o ser de caos é colocado no abismo. Essa topografia está na cultura como uma referência de ordenação e desordem. O caos se estabelece por conta da transgressão do que

Não é propósito deste trabalho entrar na discussão sobre o culto ao imperador e sua relação com o capítulo 13. Contudo, para uma discussão a esse respeito, ver Steven, 2003, p. 49-64. Quanto às relações das imagens com o tema do Nerus redivivus, ver Peerbolte, 1996, p. 144-166. 
estava estabelecido e volta ao seu estado com o restabelecimento dos lugares cósmicos, como mostram as narrativas enoquitas. No entanto, essa ordenação de 20,1-3 é temporária, pois somente se estabelecerá de uma vez por todas, em linguagem escatológica, no julgamento de todas as coisas e das próprias formas da desordem que insistem na sua presença desastrosa (20,7-8). Os capítulos 21-22 são a realização final da ordenação.

Na semiosfera judaica, as narrativas da apocalíptica descreviam a instauração do caos com imagens de seres transgredindo suas fronteiras (1 En 1-16 e sua recepção) e a sua neutralização com o aprisionamento no abismo. $\mathrm{Na}$ linguagem do livro de Apocalipse, essa desordem é novamente pintada de forma narrativa. $\mathrm{O}$ mundo no qual o visionário está não vive uma perseguição estrutural. Prevendo e descortinando, ele percebe uma realidade mais oculta, que precisa de uma sabedoria mais celestial para ser acessada. O que parece uma ordem, para o visionário é caos. E isso vai se tornar ainda pior. Como diz Fiorenza, é uma interpretação "mitopoética" da realidade (FIORENZA, 1998, p. 22). Por isso, os seus leitores implícitos são descritos como aptos a discernir e escolher entre aceitar a associação ou não com essas forças do caos. Em 18,1-3, estão os cúmplices, os beneficiados. Portanto, os seus ouvintes são incitados a deixar, e não se associar $(18,4)$, pois a estes o que lhes resta é a punição com a Prostituta $(18,4 b-8)$. Desse modo, a narrativa cria dois grupos de personagens redondos: os que estão ao lado do discurso do narrador (a mulher, os santos, os 144 mil) e os que aceitam o discurso do sistema vigente, que é caracterizado como dragão, serpente, bestas, ou seja, o próprio Satanás.

\section{Considerações finais}

O Apocalipse privilegia a visão, sendo que ela está a serviço da relação performática entre narrativa e ouvintes: as imagens são agentes performáticos. Como intui Frilingos, quando Roma é descrita como besta e prostituta, sendo finalmente destruída (17-18), ao contemplarem essas imagens literárias, os espectadores narrativos participam no horrível quadro para desafiarem a audiência a dar performance na vida (FRILINGOS, 2004, p. 40-41).

Não há possibilidade de flexibilidade. A linguagem dualista não permite meio-termo. Guiado pelo narrador, o leitor deveria construir suas relações de empatia ou antipatia com os grupos de personagens. Isso determinaria a relação de simpatia, posição positiva com o dono do discurso, representado pelo componente de cada um dos grupos. Contudo, ele é muito contundente: "ou fuja do mundo construído pelo discurso do Império ou viva a possibilidade de 
sofrimento das punições no processo da nova criação", ou seja, "associe-se ao caos ou à ordem". 5

\section{Referências}

ADRIANO FILHO, José. Caos e recriação do cosmos: a percepção do Apocalipse de João. Ribla, n. 34, 1999.

ARNDT, W.; DANKER, F. W.; BAUER, W. A Greek-English Lexicon of the New Testament and Other Early Christian Literature. Based on Walter Bauer's Griechisch-deutsches Worterbuch zu den Schriften des Neuen Testaments und der frhchristlichen Literatur. Chicago: The University of Chicago Press, 2000.

AUNE, D. E. Revelation 6-16. Dallas: Thomas Nelson, 1998 (Word Biblical Commentary 52B).

CAREY, Greg; BLOOMQUIST, Gregory, L. (Org.). Vision and Persuasion: Rhetorical Dimensions of Apocalyptic Discourse. St. Louis: Chalice, 1999.

COLLINS, A. The Combat Myth in the Book of Revelation. Eugene: Wipf and Stock Publishers, 2001.

COLLINS, J. Pseudonymity, Historical Reviews and the Genre of the Revelation of John. Catholic Biblical Quarterly, v. 39, n. 3, p. 329-343, jul. 1977.

DUFF, Paul. Who Rides the Best? Oxford: Oxford University Press, 2011.

FIORENZA, Elisabeth Schüssler. The Book of Revelation: Justice and Judgment, 2. ed. Minneapolis: Fortress Press, 1998.

. Babylon the Great: A Rhetorical-Political Reading of Revelation 17-18. In: BARR (Org.). The Reality of Apocalypse: Rhetoric and Politics in the Book of Revelation. Atlanta: Society of Biblical Literature, 2006.

FRILINGOS, Christopher A. Spectacles of Empire: Monsters, Martyrs, and the Book of Revelation. Philadelphia: University of Pennsylvania Press, 2004.

GRAULUND, Rune; EDWARD D. J. The Grotesque. London; New York: Routledge, 2013 (The New Critical Idiom).

HANSON, P. The Dawn of Apocalyptic: The Historical and Sociological Roots of Jewish Apocalyptic Eschatology. Philadelphia: Fortress Press, 1983.

KITTEL, G.; FRIEDRICH, G.; BROMILEY, G. W. (Org.). TDNT. Grand Rapids: W. B. Eerdmans, 1995, v. 4.

MESTERS, C.; OROFINO, F. O Apocalipse de São João: a teimosia da fé dos pequenos. Petrópolis: Vozes, 2002.

Para uma exposição desse dualismo como um uso retórico em uma perspectiva de gênero, cujo quadro, especialmente em 17-19, mostra a figura feminina associada às forças do caos, ver Fiorenza, 2006, p. 243-269. 
NEWSOM, Carol A. The Development of 1 Enoch 6-19: Cosmology and Judgment. The Catholic Biblical Quarterly, n. 42, p. 310-329, 1980.

NOGUEIRA, Paulo Augusto de Souza. Imagens de violência no Apocalipse de João: os demôniossoldados de Apocalipse 9. In:

Experiência religiosa e crítica social no cristianismo primitivo. São Paulo: Paulinas, 2003.

PEERBOLTE, L. J. Lietaert. The Antecedents of Antichrist: A Traditio-Historical Study of the Earliest Christian Views on Eschatological Opponents. Leiden; New York; Köln: E. J. Brill, 1996, p. 144-166.

RICHARD, Pablo. Apocalipse: reconstrução da esperança. Petrópolis: Vozes, 1996.

ROLOFF, Jürgen. The Revelation of John: A Continental Commentary. Minneapolis: Fortress Press, 1993.

STEVEN J. Friesen. The Beast from the Land: Revelation 13:11-18 and Social Setting. In: BARR, David L. (Org.). Reading the Book of Revelation. Atlanta: Society of Biblical Literature, 2003.

THOMPSON, Leonard L. A Sociological Analysis of Tribulation in the Apocalypse of John. Semeia, n. 36, p. 147-174, 1986.

. Ordinary Lives: John and his First Readers. In: BARR, David L. (Org.). Reading the Book of Revelation. Atlanta: Society of Biblical Literature, 2003.

Press, 1990.

The Book of Revelation: Apocalypse and Empire. New York: Oxford University 